\title{
A Study on the Curriculum Design of Personalized English Teaching in the Context of Internet
}

\author{
Youyan Xu \\ College of Foreign Languages, Guizhou University, Guiyang, China \\ Email: 1565730049@qq.com
}

How to cite this paper: Xu, Y. Y. (2021). A Study on the Curriculum Design of Personalized English Teaching in the Context of Internet. Open Journal of Social Sciences, 9, 65-71.

https://doi.org/10.4236/jss.2021.94007

Received: February 25, 2021

Accepted: April 11, 2021

Published: April 14, 2021

Copyright $\odot 2021$ by author(s) and Scientific Research Publishing Inc. This work is licensed under the Creative Commons Attribution International License (CC BY 4.0).

http://creativecommons.org/licenses/by/4.0/

\section{(c) (i) Open Access}

\begin{abstract}
This paper focuses on the new practice and new development of learning science, makes a comprehensive analysis of the theoretical basis, basic connotation and educational significance of the personalized learning by using the method of literature review, and deeply analyzes the current status of university curriculum design and the existing problems from the perspective of personalized learning. On this basis, this paper puts forward the construction strategy of English courses curriculum design based on personalized learning, and hoping to have the students the active learner in the classroom and develop harmoniously as well as make the curriculum construction in a virtuous ecological circle.
\end{abstract}

\section{Keywords}

Big Data, Personalized Teaching, College English

\section{Introduction}

For a long time, cultivating students' innovative spirit and practical ability has been the focus of national quality education. The research results of "Chinese students' development core accomplishment" point out that the core accomplishment is to cultivate "all-round development person", and its training goal is divided into three aspects: cultural foundation, independent development and social participation. The comprehensive expression is humanistic background, scientific spirit, learning to study, healthy life, responsibility bearing and practical innovation (Zhu Zhiting \& Shen Demei, 2013).

It can be seen that training students to learn and promote their independent development is the implementation of core literacy. When the development of 
educational informatization enters a new stage with the core demand of effectively supporting teaching and learning and promoting students' individualized development, it is necessary to provide learners with a new learning mode to meet their individual needs in order to support their independent development. As an advanced stage of deep integration of technology and education, individualized learning can promote learners' ability and personality

In the process of learning activities to get full, free, harmonious development.

Personalization of English teaching is an important practical direction of English teaching reform. In October 2014, the $7^{\text {th }}$ International Seminar on English Teaching in China, held at Nanjing University, defined the theme of the conference as "the reform and research of Chinese English teaching oriented to localization and individuation". At the meeting, Professor Wang Shouren (2015) discussed some concepts and methods of individualized English teaching. As a matter of fact, the so-called individualized English teaching is not a teaching method, but a direction, that is, different teaching contents and methods are selected for learners' language level, personality, learning style, learning needs and so on.

Although the importance of individualized learning has become a consensus, the current talent training model is still far from the ideal of individualized learning. It is necessary to promote the transformation and development of school education on the basis of students' individualized learning. Build a talent training mechanism to promote students' individualized learning. Based on the theory of individualized learning, this paper aims at the problems and shortcomings of the current English curriculum system in colleges and universities in China, and constructs a curriculum design model with students as the center and the goal of promoting students' individualized learning, so as to promote the transformation and development of higher education.

\section{Research Background}

\subsection{The Connotation, Characteristics and Significance of Individualized Learning}

The core elements of the concept of personalized learning include: first, Advocating that students' personality characteristics such as learning style, needs, interests, talent, social and cultural background as the premise and foundation of education and teaching, This is also the core value of personalized learning: second, Embodies the student center education idea, Advocate placing students at the centre of the education system, Giving students the right and freedom to choose, Emphasis on the adaptability of education and teaching and the role orientation of serving students; Finally, Advocate the achievement level of students as the ultimate goal of education, Whether it's a knowledge achievement, Or the student's own potential, Its direction is the student individual. It can be seen that individualized learning adheres to the student-centered educational concept, Respect the rules of learning and growth, Advocating that according to 
the learner's learning style, learning needs, experience background, interest, attitude, motivation and other personality characteristics, Personalized learning guidance and help, In order to promote the improvement of students' learning ability and the development of personality. Researchers Peggy and Dale Basye believe that, Successful individualized learning includes seven characteristics: 1) integrating students' interests and abilities into real-world activities, To facilitate their learning by standards in the content field; 2) The role of teachers as facilitators and coaches, rather than merely disseminating knowledge; 3) Learners control their learning paths, And set your own goals, Building self-efficacy; 4) Technology can support learners in choosing what they have learned, how to learn and how to demonstrate their learning; 5) Supported by digital tools, Will form an evaluation throughout the learning cycle, Help teachers and learners understand their strengths and weaknesses; 6) Measuring progress in subject content by demonstrating learners' skills and understanding; 7) Integration of technology through the experience of teachers and learners, To better support learning.

\subsection{Current Situation of Traditional English Teaching Environment}

\subsubsection{Unified Teaching Resources, Lagging Behind}

At present, most of the textbooks are written in a unified way, and the corpus is too old to resonate with English learners. Cheng Jianlin (2007) pointed out that the current college English teaching materials "are basically completed by $2004 . .$. Although the current English teaching materials are constantly revised, due to the limitation of the overall framework, the concept of writing and the length of writing, there will be an awkward situation of "one publication will lag behind", which can not meet the individualized needs of students.

\subsubsection{Teaching Method Is Single, Classroom Lacks Interactive Communication}

In the process of traditional college English teaching, teachers play a leading role. Teachers pass the contents of teaching materials through their own understanding, induction and supplement, form teaching plans and handouts, and pass on the book knowledge to students. The classroom is basically a teacher's "arbitrariness", and there is little interaction between teachers and students. This will inevitably cause teachers' job burnout and ultimately affect the teaching effect. At the same time, students are in the position of passive acceptance, it is difficult to really turn language input into language output, so the phenomenon of "dumb English" is very serious.

\subsubsection{Academic Evaluation Style Is Single, Examination-Oriented Psychology Is Strong}

The traditional college English teaching adopts the summative evaluation method, the basic method is mostly a test paper of the final examination, but this evaluation method is too utilitarian to objectively and dynamically reflect the students' comprehensive performance in the whole teaching process. The devel- 
opment value of middle school students in the teaching process is ignored. Learners are very difficult to their own interests as the starting point, often based on the task of schools, teachers as the basis of the choice of courses, choose the direction of efforts, their personality can not be fully developed. Students have a strong psychological test, English learning is mainly for the examination, which also leads to low students' English application ability.

\section{Personalized English Teaching in the Context of Internet+}

\subsection{Teachers and Students Build Learning Resources Together}

In the curriculum design, we build a learning library for the students by using the Internet. The students can search listening, speaking, reading, writing and translating related knowledge and information based on classification. Meanwhile, the students can join in the construction of the learning resources and participate in the curriculum design.

Through participation, the initiative and enthusiasm of the students are enhanced. The students become a part of a curriculum and dominate the learning. Therefore, the improvement of the learning capacity and comprehensive quality of the students is promoted.

Internet+ makes the presentation of knowledge change from "layered" to "mesh". Driven by big data analysis technology, knowledge map, ability map and so on, digital education resources will be structurally reorganized to form systematic, structured and adaptive digital education resources. To provide teachers and students with rich, diverse, virtual combination of educational resources and environment and diversified, accurate, humanized learning support services. The learning environment system, which is rich in learning resources and combined with virtual reality, supports ubiquitous learning activities, reshapes teachers' roles, develops individualized teaching and tutoring, and realizes students' individualized learning. Learners can choose their own learning materials according to their own learning style and learning situation, and choose the most suitable learning resources to meet the needs of personalized learning diversity, flexibility and dynamic. The network and cloud storage platform can provide learners with massive, immediate and vivid English learning resources with novel themes, wide coverage and easy acceptance. The establishment of a hybrid teaching three-dimensional network and the effective integration of educational resources online and offline can provide students with comprehensive, detailed, accurate, rich and diversified learning resources, thus improving the level of English teaching.

\subsection{Mixed Teaching Mode Combining Online and Offline, Flexible and Autonomous Teacher-Student Interaction}

Hybrid teaching is the combination of the advantages of traditional learning methods and the advantages of digital or network learning. Its essence is the integration of teachers, students and learning resources (Garrison \& Kanuka, 2004: 
p. 234). This teaching mode not only plays the leading role of teachers' guidance, inspiration and monitoring in the teaching process, but also fully embodies the enthusiasm, initiative and creativity of students as the main body of the learning process. Interactive communication between teachers and students and students in hybrid teaching has been greatly enhanced. They can use instant messaging tools such as QQ or WeChat for online interaction, or open interactive sections on online learning platforms, or use e-mail, etc. The development of information technology has made it easy for teachers and students to interact asynchronously, to answer questions, to cooperate in learning, to communicate and discuss. As part of the content of the knowledge transfer part is undertaken by online learning after class, there will be more time for various interactive activities in the face-to-face classroom. In the classroom than in-depth communication content can continue to the class through online space to continue. The combination of synchronous interaction and asynchronous interaction greatly increases the opportunity of interaction. In the mixed teaching mode, teaching implementation is divided into two parts: face-to-face classroom teaching and online learning. Before the implementation of teaching, teachers build a mixed learning environment for students and build mixed learning resources. In the implementation of teaching, teachers should design and organize teaching activities. In the classroom teaching part, the main behavior of teachers includes stimulating students' learning motivation; analyzing and explaining the contents of the course, highlighting the key and difficult points, guiding students' learning methods; interactive communication between teachers and students to achieve the construction of meaning; after class, Teachers reflect on classroom teaching. In the online learning section, the main behaviors of teachers include providing resources to help students make personalized choices; expanding learning of curriculum content, organizing students to interact and promote each other online; organizing students to complete learning feedback, Online communication and output of cultural knowledge learned. In the mixed teaching mode under the background of Internet+, teachers and students are not a single transmission relationship, but a multi-directional multi-point nonlinear interaction between students, teachers and students, teachers and students and the Internet.

\subsection{Real-Time and Dynamic Multiple Evaluations}

The traditional teaching evaluation tries to improve the students' learning results through teachers' continuous improvement of offline strategies, but also stays in the cognitive stage of teachers leading the whole teaching. With the wide application of information technology and advanced learning theory, learning evaluation should not only provide teachers with improved teaching strategies, but also provide individualized and visual evaluation to promote the construction of students' autonomous knowledge. The contents of the evaluation of students' learning include the evaluation of course content, the analysis and evaluation of participation in interactive communication, the evaluation of examination and 
learning works, and the evaluation of learning outside resources. The content of the course is mainly to evaluate the knowledge points learned. The evaluation information includes the length of study, the knowledge points learned, the number of learning points and the learning notes; the participation in interactive communication analysis and evaluation is mainly to evaluate the students' classroom activities and extracurricular interaction. The information includes the number of questions published in the learning space, the number of questions answered, the number of topics of interactive communication, etc. The evaluation of examination and learning works is the evaluation of students' learning works and unit tests, and the evaluation of learning works includes the evaluation of individual works and group works; The evaluation of extracurricular learning resources includes the evaluation of students in the extended resources of formal and informal learning, including the download amount of text, the click amount of video, etc.

Digital learning evaluation based on big data makes learning evaluation go to multiple evaluation and deep evaluation. Evaluation no longer depends solely on classroom observation and learning test, but is based on students' learning behavior in the process of learning. This can observe more details in students' learning process and give teachers, learning system developers and students more detailed feedback information, which is conducive to better promoting students' knowledge mastery and ability development.

\section{Conclusion}

"Internet+" has been widely used in the field of education, and individualized teaching is the trend of education. This paper discusses the changes of English teaching under this background and how to implement individualized teaching more effectively. In this case, English teaching practitioners and planners must change their thinking concepts, renew curriculum design, adjust teaching roles, and truly teach students according to their aptitude, so as to promote the development of college English teaching in the new period.

\section{Funding}

Foundation project: this paper is the research result of "individualized English Teaching Research based on big data Application" in the 2016 Planning Project of Humanities and Social Sciences of Guizhou Education Department (gh11. 2016).

\section{Conflicts of Interest}

The author declares no conflicts of interest regarding the publication of this paper.

\section{References}

Cheng, J. L. (2007). The Contemporary Situation and Reform about the College English. 
Foreign Language and Foreign Language Education, No. 5, 22-29.

Garrison, D. R., \& Kanuka, H. (2004). Blended Learning: Uncovering Its Transformative Potential in Higher Education. The Internet and Higher Education, 7, 95-105. https://doi.org/10.1016/j.iheduc.2004.02.001

Wang, S. R. (2015). Concept and Practice of Personalized English Teaching in Contemporary Chinese Context. Foreign Language and Foreign Language Education, No. 4, 5-10.

Zhu, Z. T., \& Shen D. M. (2013). A New Paradigm of Educational Technology Research Based on Big Data Audio-Visual Education Research. Foreign Language, No. 10, 5-13. 